\title{
FATORES ASSOCIADOS À CONDIÇÃO DE ACAMADO EM IDOSOS DOMICILIADOS
}

Clóris Regina Blanski Grden; Universidade Estadual de Ponta Grossa; reginablanski@hotmail.com

Ana Flávia Lourenço Loiola; prefeitura Municipal de Ponta Grossa; flavinhaloiola@hotmail.com

Daniele Bordin; Universidade Estadual de Ponta Grossa; daniellebordin@hotmail.com

Taís Ivastcheschen; Universidade Estadual de Ponta Grossa; taisiivastcheschen@gmail.com Luciane Patrícia Andreani Cabral; Hospital Universitário Regional dos Campos Gerais; luciane.pacabral@gmail.com Everson Augusto Krum; Universidade Estadual de Ponta Grossa; eak@uepg.br

\section{RESUMO}

Introdução: o acelerado envelhecimento da população acarreta desafios aos sistemas de saúde, uma vez que os idosos apresentam elevada prevalência de doenças crônicas, as quais podem evoluir para declínio da capacidade funcional e cognitiva. Nesta conjuntura, espera-se o aumento de idosos na condição de acamados e com elevado grau de dependência. Objetivo: identificar os fatores associados à condição de acamado entre idosos brasileiros. Métodos: estudo transversal, com dados secundários provenientes de inquérito base populacional nacional, com idosos $(n=11.177)$. A pesquisa foi de base domiciliar por meio de amostragem probabilística por conglomerados em três estágios, sendo o conjunto de setores censitários as unidades primárias de amostragem, os domicílios as unidades secundárias e moradores maiores de idade selecionados, as unidades terciárias A condição de acamado foi considerada variável dependente e as características sociodemográficas e condições de saúde como independentes. Para análise empregou-se o teste de regressão logística. Resultados: verificou-se que 4,9\% dos idosos eram acamados e que esta condição mostrou-se associada ao analfabetismo $(\mathrm{OR}=1,38)$, quantidade de doenças crônicas, episódio de acidente vascular encefálico $(\mathrm{OR}=1,46)$, diagnóstico de hipertensão arterial sistêmica $(\mathrm{OR}=1,49)$, alterações nos níveis de colesterol $(\mathrm{OR}=1,45)$, precisar de algum atendimento relacionado a própria saúde $(\mathrm{OR}=4,22)$, internamento $(\mathrm{OR}=3,06)$ e atendimento emergencial no domicílio nos últimos 12 meses $(\mathrm{OR}=1,76)$. Conclusão: o estudo permitiu identificar importantes fatores associados à condição acamado de idosos brasileiros com destaque para as variáveis clínicas. Os achados poderão subsidiar o planejamento dos cuidados gerontológicos voltados às necessidades específicas desse segmento etário.

Palavras-chave: Saúde do idoso; Pessoas acamadas; Enfermagem geriátrica. 